\title{
Sabina Deweik, Pioneira do Coolhunting no Brasil
}

- Sheila Fernanda Bona ${ }^{1}$

- Célio Teodorico dos Santos² 


\title{
Sabina Deweik, Pioneira do Coolhunting no Brasil
}

\section{RESUMO}

Esta é uma entrevista com Sabina Deweik, coolhunter (caçadora de tendências) e especialista em captar mudanças sociais, na qual a entrevistada falou sobre a metodologia de pesquisa de coolhunting (caçar tendências), pesquisa de comportamento do consumidor e sobre como as empresas podem se beneficiar através desta consultoria especializada. Sabina contou ainda sua trajetória profissional e como enveredou para a área de pesquisa de tendências, tornando-se precursora do coolhunting no Brasil nos anos 2000, apontando quais foram as principais dificuldades enfrentadas no início da carreira, bem como, quais são as atribuições necessárias para o profissional caçador de tendências. Finalizou falando sobre o Zeitgeist (Espírito do Tempo) da sociedade atual e a prospecção de movimentos sociais emergentes.

Palavras-chave: coolhunting, tendências, sociedade.

\section{Sabina Deweik, Pioneer of Coolhunting in Brazil}

\begin{abstract}
This is an interview with Sabina Deweik, coolhunter and specializes in capturing social changes, in which the interviewee said about the research methodology of coolhunting, consumer behavior research and about how companies can benefit from this expert advice. Sabina also said her professional trajectory and how has moved to the trend research area, becoming precursor of coolhunting in Brazil in 2000's, pointing out which the main difficulties faced in the beginning of the career, as well as what are the attributions necessary for the professional coolhunter. Finalized talking about the Zeitgeist (Spirit of the Times) current of society and the prospect of emerging social movements.
\end{abstract}

Keywords: coolhunting, trends, society. 


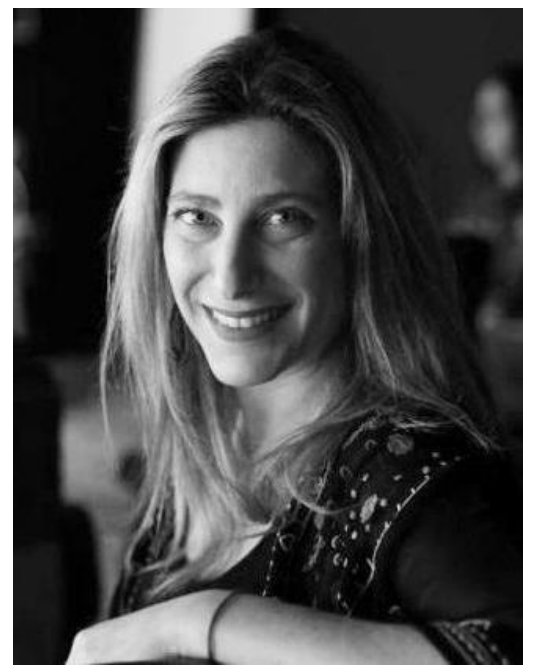

Figura 1: Sabina Deweik.

Fonte: Arquivo pessoal (2017).

\section{APRESENTAÇÃO}

Nesta entrevista abordaremos o coolhunting como método de pesquisa de tendência, com o propósito de esclarecer o que é esta metodologia, como surgem as tendências sociais e quem é o profissional responsável por essas pesquisas. Além disso, buscou-se apresentar quais são os benefícios para as empresas e organizações que utilizam esta consultoria especializada.

E para atingir tal objetivo entrevistou-se Sabina Deweik que é coolhunter (caçadora de tendências), pesquisadora, consultora estratégica, coach ontológica, palestrante e educadora. Ela atua há mais de dezessete anos na área e tornou-se referência em pesquisa de tendências e comportamento do consumidor. Formouse em Jornalismo pela PUC-SP e tem em seu currículo dois mestrados: um em Comunicação e Semiótica pela PUC-SP e outro em Fashion Communication pela Domus Academy - Milão - Itália. Nos anos 2000 foi pioneira ao introduzir a metodologia de coolhunting (caçar tendências) no Brasil, sendo correspondente do renomado Future Concept Lab, com sede em Milão Itália, atuando mais tarde como diretora do Instituto no país. Movida pela paixão que encontrou pelo trabalho, criou o primeiro curso na área de coolhunting no Brasil no Istituto Europeo di Design e mais tarde também na Escola São Paulo. 
Atualmente, a coolhunter presta consultoria estratégica especializada em tendências e comportamento do consumidor para que empresas, organizações e indivíduos prospectem estratégias inovadoras e se adequem aos novos tempos. Dedica-se também a realizar palestras sobre o coolhunting $\mathrm{e}$ inovação, além de ministrar workshops para formação de coolhunters.

\section{ENTREVISTA}

\section{A. $O$ que é coolhunting? $O$ que faz um coolhunter? Quais são as habilidades e conhecimentos que este profissional deve possuir?}

O coolhunting (caçar tendências) é uma metodologia que capta os sinais emergentes da sociedade em termos de comportamento, interpreta essas informações e através disso gera tendências, que ajudam a antecipar movimentos futuros. O coolhunter é o caçador de tendências, um profissional que se dedica a observar e captar esses comportamentos, fazendo isso através da leitura de sinais observados na sociedade, em várias áreas diferentes, como: moda, design, arquitetura, sustentabilidade, novos espaços culturais, mobilidade urbana, gastronomia, música, arte. Esse profissional capta estes comportamentos e analisa quais são os padrões repetitivos presentes na sociedade e através destes despontamentos de sinais recorrentes, surgem as tendências. Desta forma, o coolhunter é capaz de detectar estes sinais repetitivos e traduzí-los em tendências antes mesmo deste comportamento se consolidar como desejo no cotidiano do consumidor.

Acima de tudo um coolhunter deve ser uma pessoa curiosa, ser observador, intuitivo, estar atualizado e informado sobre o que está acontecendo na sociedade em geral. Normalmente são pessoas com formação em áreas de Comunicação e Ciências Humanas, porém não necessariamente. Podem fazer cursos de pós-graduação voltados ao comportamento 
do consumidor, antropologia do consumo e até mesmo semiótica. Atualmente, existem bons cursos e workshops direcionados para a área de coolhunting.

\section{B. Você possui formação em Jornalismo, e também mestrados na área de Semiótica e Comunicação em Moda, então como esse enveredamento para a área de pesquisa de tendências se deu na sua carreira?}

Comecei minha carreira profissional no jornal Estado de São Paulo - Espaço de Cultura - Caderno 2. Neste momento estava acontecendo a profissionalização da Moda no Brasil. Comecei a cobrir os desfiles de moda como o Phytoervas Fashion, depois o Morumbi Fashion que mais tarde veio a ser o SPFW São Paulo Fashion Week, o Mercado Mundo Mix (Feira itinerante de Moda). O meu primeiro contato com tendências, de fato se deu através destas coberturas jornalísticas de Moda, quando eu observava essas informações de tendências de moda e analisava principalmente o comportamento por trás destas manifestações.

Fiz mestrado em Comunicação de Moda em Milão - Itália, onde conheci Francesco Morace sociólogo e presidente de um dos institutos mais importantes de pesquisa de comportamento e tendências, o Future Concept Lab. O Francesco me convidou para fazer um teste de caçadora de tendências no Brasil, então ele me contratou para ser correspondente do instituto no país. A partir disso, eu percebi que tudo o que eu havia imaginado e gostava de fazer de fato tinha um nome, jeito certo de fazer, ou seja, era uma profissão no qual agregava tudo aquilo que eu acreditava.

Comecei a trabalhar definitivamente como coolhunter no ano de 2000 e trouxe esta metodologia para o Brasil. Como correspondente Future Concept $L a b$, aos poucos fomos prospectando o instituto e os benefícios de inserir a pesquisa de mercado e tendências para as empresas. Tivemos grandes clientes 
como Havaianas, Fiat, Natura, Grendene, Petrobrás, Senai Cetiqt, Sebrae, H.Stern entre outras empresas.

C. Você foi umas das pioneiras ao introduzir o coolhunting no Brasil. Quais foram as principais dificuldades iniciais para a profissionalização da atividade?

Nos anos 2000, as empresas brasileiras não entendiam os benefícios da consultoria especializada na área de pesquisa de tendência e consumo e de como isso poderia refletir em ganhos financeiros, em termos de resultado. Era ainda uma profissão não compreendida aqui no país. Então, de início eu trabalhei mais para empresas estrangeiras que pretendiam empreender aqui no Brasil e contratavam o Future Concept $L a b$ na Itália. Com tudo, através de persistência, isso me consolidou como uma precursora do coolhunting no país. Atualmente, o coolhunter se firmou como uma das profissões do futuro e a atividade vêm sendo cada vez mais reconhecida e valorizada. Outro fator facilitador é a tecnologia das ferramentas de trabalho existentes hoje, pois ampliaram a velocidade de comunicação e a mobilidade.

\section{Quais são os benefícios que a consultoria} especializada em tendências e comportamento de consumidores podem trazer para as organizações?

Hoje em dia, as pessoas e as empresas entendem melhor os benefícios de trabalhar com pesquisa de consumidor e dar atenção aos sinais emergentes. De fato, a inovação hoje é uma questão de sobrevivência no mercado. O coolhunting tem a capacidade de entender o que está acontecendo no presente e os sinais emergentes para poder prospectar movimentos futuros, com isso as empresas conseguem criar estratégias de produto, comunicação, vendas, marketing de varejo. Conseguem entender também melhor o seu próprio consumidor, que antes de mais nada são verdadeiramente pessoas. 


\section{E. Qual a importância da pesquisa de campo e a pesquisa digital na atividade de coolhunter?}

A pesquisa de campo é extremamente importante, pois ela ativa todos os cinco sentidos do pesquisador no universo que está sendo pesquisado. A pesquisa de campo proporciona muitas vezes sinais inesperados e importantes, é possível observar e conversar com as pessoas que estão naquele ambiente. A pesquisa digital também é importante, pois você tem acesso a informações de nível global que complementam a pesquisa. Serve também para fazer uma pesquisa prévia, para entender melhor o que será pesquisado, para se munir de informações e conhecimento sobre o assunto.

\section{F. Na sua experiência profissional e perspectiva, qual seria Zeitgeist (espírito do tempo) da sociedade atual?}

Estamos em uma era de transição na busca pelo sentido e propósito de vida. Algo está mudando na questão de paradigmas anteriores e a nossa sociedade como um todo aos poucos está cedendo para novos valores. Estão emergindo novas formas de agir, de pensar, de trabalhar. Até então se acumulava muito, atualmente por conta da economia criativa, do compartilhamento e do cocriar, surgiram novos modelos de negócio, como: Uber, Alibabá, Airbnb. Passamos do modelo da posse para o modelo do acesso e isso é uma grande mudança, não só de mentalidade como também econômica.

As novas gerações já não querem mais adquirir bens e sim experiências, compreendem melhor e aceitam muito mais as questões de diversidade social. A tecnologia vem crescendo trazendo a robótica, a realidade virtual, o digital e por outro lado vem surgindo uma contra tendência para um retorno a simplicidade, a desconexão, a meditação em busca do autoconhecimento. 